ORIGINAL ARTICLE

\title{
The influence of motor skills on the short sprint results
}

\author{
Nikola Aksović ${ }^{1 \mathrm{ABDE}}$, Iryna Skrypchenko ${ }^{2 \mathrm{ADE}}$, Bojan Bjelica ${ }^{3 \mathrm{ACD}}$, R. Ram Mohan Singh ${ }^{4 \mathrm{ADE}}$, Filip Milanovićs ${ }^{5 \mathrm{ACD}}$, \\ Dejan Nikolić5, $6 \mathrm{BCD}$, Milan Zelenovićc ${ }^{\mathrm{BCD}}$ \\ ${ }^{1}$ Faculty of Sport and Physical Education, University of Niš, Serbia \\ ${ }^{2}$ Department of Physical Education \& Tactical and Special Training, Dnipropetrovsk State University of Internal \\ Affairs, Ukraine \\ ${ }^{3}$ Faculty of Physical Education and Sport, University of East Sarajevo, Bosnia and Herzegovina \\ ${ }^{4}$ Department of Physical Education \& Sports, Pondicherry University, India \\ ${ }^{5}$ University Children's Hospital, Belgrade, Serbia \\ ${ }^{6}$ Faculty of Medicine, University of Belgrade, Serbia
}

Author contributions: A - Study design; B - Data collection; C - Qualitative analysis; D - Manuscript preparation; E Funds Collection

\begin{abstract}
Background The curriculum of physical education in high schools is based on learning motor skills, as well as their and Study Aim development in sports sections, where the 100-meter sprint dominates. The aim of the study was to determine the influence of motor skills on the $100 \mathrm{~m}$ running results.

Material and The research was conducted on a sample of 80 high school students in Novi Pazar and Kraljevo, aged 16 Methods and 17 years ( \pm 6 months). 12 variables were used to assess motor skills, three variables each: explosive power, segmental speed, repetitive power, and flexibility (standing long jump), triple jump, five jumps. For estimating segmental speed: foot tapping, hand tapping, foot tapping on the wall. For the assessment of repetitive power: lifting the torso on the Swedish bench, mixed pull-ups, squats. To assess flexibility: deep bench press, twine, stick twist.

Results Results were obtained to confirm that there is a positive influence of motor skills on the $100 \mathrm{~m}$ sprint results at the level of $(p=.000)$. The results in the $100 \mathrm{~m}$ sprints are statistically significantly dependent on the motor skills that manifest segmental speed and explosive power. Variables (standing long jump, foot tapping on the wall and foot tapping) have a statistically significant effect on the criterion variable of the 100 m sprint.

Conclusions: Recommendation to future researchers would be to conduct a study over a longer period of time with the aim of examining the biomechanical factors that determine the success in sprint, is the production of force in the phase of sprint acceleration and sprint deceleration.

Keywords: students, teaching, athletics, explosive strength, speed
\end{abstract}

\section{Introduction}

Physical education classes in secondary schools are based on learning motor skills $[1,2]$. As physical education is inadequately represented by the weekly number of hours (two hours), teaching is realized with a low energy component, which is a big problem in achieving the goal and tasks of teaching physical education. Due to such insufficient efficiency of physical education classes, a larger number of children are included in additional exercises within the school section for physical education or in training work in sports organizations. In order to improve the teaching process in secondary schools, research that determines the impact of anthropological status on the specific motor abilities of secondary school students is of scientific interest. Motor skills as the most important factor of anthropological status in the teaching of physical education are mainly related to the influence and relations with other segments: motor, morphological, functional, etc. The importance of anthropology and morphology in attaining better motor fitness including

\footnotetext{
(a) Nikola Aksović, Iryna Skrypchenko, Bojan Bjelica,

R. Ram Mohan Singh, Filip Milanović, Dejan Nikolić,

Milan Zelenović, 2021
}

doi:10.15561/26649837.2021.0607 sprint and the use of motor tests to enhance performance is well documented $[3,4]$. One of such segments is the short sprint, which is the subject of research in this article.

Numerous studies showed to a positive relationship between motor skills, and short sprint results [6,9]. Recent research also indicates that short sprints are a success factor in a number of sports $[10,14]$. The most important factors for achieving high results of short sprints are good technique, speed of alternative movements, explosive power as well as maximum force of tried movements [5]. Given the high rate of innate speed (90-95\%) training can have very little effect on its development $[15,16]$. Studies have also established a predictive association between motor skills and sprints in statistical terms [17]. However, this does not mean that the development of speed should not be influenced, especially in terms of its complex manifestation, but it should be realistic in expectations. Therefore, speed training is mainly focused on the development of reaction speed, the speed of performing one movement and the speed of alternative (frequency) movements. For the development of specific speed, the intensity of technical-tactical exercises is maximum. The pause between repetitions in one series is $1-3$ s (for 
reaction speed and speed of one movement) or none at all (for movement frequency). The number of repetitions in one series depends on the task being performed and the preparedness of an athlete, usually (10-15), while the amount of series per task is (3-5). The pauses between series should be long enough to ensure that the performance speed will be at the level of the previous one [5]. It should be noted that the application of different training methods (for example, plyometric training, resistance training) in a long period of time has a positive effect on the development of short sprints $[18,19]$.

At the beginning of a sprint run, the ability to generate high concentric force and generate high speed during acceleration is of primary importance for success in short sprints. Shen [20] showed that a $100 \mathrm{~m}$ sprint can be divided into 3 different phases: acceleration, maximum speed and deceleration. The acceleration phase can be divided into several sub-phases: initial or initial acceleration $(0-12 \mathrm{~m})$, which is mainly characterized by a constant increase in stride length and main acceleration $(12-35 \mathrm{~m})$. When the acceleration phase is of sufficient length and the optimal value of the driving speed, the sprinter is not able to maintain the maximum speed and a long deceleration phase occurs [20]. Professional sprinters reach a maximum speed between $(50-70 \mathrm{~m})$, and are capable of crossing another $(20 \mathrm{~m})$, or rarely (30 m) [21]. Thus, the third transition sub-phase (35-60 $\mathrm{m})$ takes place only at the elite level and lasts until the sprinter reaches the level of maximum running speed. At this stage, the sprinter reaches the maximum stride length, stride frequency and maximum speed. The deceleration was marked only by the last $(10 \mathrm{~m})$ of the $100 \mathrm{~m}$ sprint [22]. The aim of the study was to determine the influence of motor skills on the $100 \mathrm{~m}$ running results.

\section{Material and Methods}

\section{Participants}

The research was conducted on a sample of 80 high school students in Novi Pazar and Kraljevo, aged 16 and 17 ( \pm 6 months). All participants conducted their activity in regular physical education classes and with three hours a week training process as selected athletes as part of additional classes. The subjects included in the research were healthy and without any chronic diseases, heart problems, is without injuries of the locomotor system that would affect the test results.

Research Design

A total of 12 tests were used to assess motor skills, three tests each: explosive power, segmental speed, repetition power and flexibility [23]. For the assessment of explosive power: standing long jump (MSDM), triple jump (MTRS), five jumps (MPTS). For estimating segmental speed: foot tapping (MTAN), hand tapping (MTAR), foot tapping on the wall (MTAZ). For the assessment of repetitive power: lifting the torso on the Swedish bench (MDTK), mixed pull-ups (MMZG), squats (MČUČ). To assess flexibility: deep bench press (MDPK), twine (MŠPA), stick twist (MISP). A $100 \mathrm{~m}$ sprint was used to evaluate the results of running speed [24].

\section{Statistical Analysis}

The data obtained by the previously described procedure were processed by the SPSS 17 statistical program (Statistical Package for Social Science, v17.0, SPSS Inc., Chicago, IL, USA). Basic descriptive parameters were used for data processing: arithmetic mean (Mean), minimum value (Min), maximum value (Max), standard deviation (SD), asymmetry measures (Skewness and Kurtosis).

Regression analysis in this study was used to determine the influence of motor skills (predictor system), on the 100 $\mathrm{m}$ sprint results (criterion system). Relevant parameters were calculated for regression analysis: correlation coefficient (R); partial correlation coefficient (Part-R); standardized partial regression coefficient (Beta); multiple correlation coefficient $(\mathrm{R})$; coefficient of determination $\left(\mathrm{R}^{2}\right)$; value $\mathrm{F}$ - ratio $(\mathrm{F})$; level of significance $(\mathrm{p})$; The significance level was set at $\mathrm{p}<0.05$.

\section{Results}

The results found in the Table 1 in the subjects in the area of motor abilities of the subjects show that in none of the tests there are significant deviations of the results from the normal distribution. There are at least five standard deviations (SD) in the intervals of minimum (Min) and maximum (Max) results, which indicates a significant dispersion, i.e., sensitivity of motor tests. The values of Skewness show that there are no significant deviations of the results from the normal distribution in any of the measures, considering that the values do not exceed 1.00 in any of the tests. The Kurtosis values in all tests are below 2.75, which indicates platykurtic distribution.

The obtained results of motor skills do not deviate from the results of similar researches verified in our country on this population of examinees, and thus the application of multivariate methods of processing the results in this research is enabled.

The results determined in the Table 2 in the subjects in the area of sprint running of the subjects show that there are no significant deviations of the results from the normal distribution. The values of Skewness show that there are no significant deviations of the results from the normal distribution, considering that the value does not exceed 1.00. The Kurtosis values in all tests are below 2.75 , which indicates platykurtic distribution. The obtained results of sprint running do not deviate from the results of similar researches verified in our country on this population of examinees, and thus the application of multivariate methods of processing the results in this research is enabled. Generalization of the results on the population from which the sample of these participants was derived is thus possible.

Based on the value of the multiple correlation coefficient $(\mathrm{R}=.81)$ in the Table 3 , it can be stated that motor skills (as a predictor system), based on the size of the coefficient $F$ ratio (5.18) and its significance $(p=.000)$, explain statistically significantly achieved in the short sprint results (TR 100). The coefficient of determination of the criterion variable $\left(\mathrm{R}^{2}\right)$ and the system of motor 
Table 1. Basic statistical parameters for the assessment of motor skills

\begin{tabular}{llllllll}
\hline Variables & $\mathbf{N}$ & Mean & Min & Max & SD & Skewness & Kurtosis \\
\hline MSDM & 80 & 183.21 & 150.00 & 255.00 & 9.17 & -0.058 & 1.310 \\
MTRS & 80 & 446.07 & 390.00 & 571.00 & 9.28 & -.599 & -0.667 \\
MPTS & 80 & 648.63 & 562.00 & 715.00 & 0.28 & 0.049 & -1.065 \\
MTAN & 80 & 28.49 & 22.00 & 39.00 & 4.16 & 0.385 & 0.739 \\
MTAR & 80 & 36.55 & 29.00 & 46.00 & 11.47 & -0.526 & -0.397 \\
MTAZ & 80 & 24.94 & 19.00 & 32.00 & 15.44 & -0.635 & 0.811 \\
MDTK & 80 & 11.62 & 8.00 & 27.00 & 6.49 & -0.142 & -0.710 \\
MMZG & 80 & 13.69 & 9.00 & 25.00 & 32.60 & 0.213 & 1.765 \\
MČUČ & 80 & 19.79 & 12.00 & 38.00 & 3.43 & -.231 & 1.275 \\
MDPK & 80 & 26.33 & 17.00 & 44.00 & 4.14 & 0.66 & 0.175 \\
MŠPA & 80 & 156.06 & 130.00 & 191.00 & 3.84 & 0.193 & 0.899 \\
MISP & 80 & 76.49 & 57.00 & 100.00 & 2.02 & 0.939 & 2.733 \\
\hline
\end{tabular}

Note: number of participants (N), arithmetic mean (Mean), minimum (Min), maximum (Max), standard deviation (SD), standing long jump (MSDM), triple jump (MTRS), five jump (MPTS), foot tapping (MTAN), hand tapping (MTAR), foot tapping on the wall (MTAZ), lifting the torso on the Swedish bench (MDTK), mixed pull-ups (MMZG), squats (MČUČ), deep bench press (MDPK), twine (MŠPA), stick twist (MISP).

Table 2. Basic statistical parameters for the assessment of 100 sprints

\begin{tabular}{llllllll}
\hline Variables & $\mathbf{N}$ & Mean & Min & Max & SD & Skewness & Kurtosis \\
\hline TR100 & 80 & 12.58 & 12.46 & 14.35 & 11.48 & 0.314 & 1.019 \\
\hline
\end{tabular}

Note: number of participants $(\mathrm{N})$, arithmetic mean (Mean), minimum (Min), maximum (Max), standard deviation (SD), 100m sprint (TR100).

Table 3. Regression analysis of motor abilities and criteria variables sprint $100 \mathrm{~m}$

\begin{tabular}{llll}
\hline $\mathbf{R}$ & $\mathbf{R}^{2}$ & $\mathbf{F}$ & $\mathbf{p}$ \\
\hline .81 & .64 & 5.18 & .000 \\
\hline
\end{tabular}

Note: multiple correlation coefficient $(R)$, coefficient of determination $\left(R^{2}\right)$, size of $F$ - relationship $(F)$, level of significance $(p)$

tests have $64 \%$ of common relations. The other $36 \%$ of the common variability explain the criterion variables contained in other dimensions of the anthropological space that were not the subject of research in this article.

The results of partial regression (Beta) and its significance (p), at the univariate level, indicate that statistically significant influence on the criterion variable (TR 100), have the following motor variables: standing long jump (MSDM .002), foot tapping on the wall (MTAZ .003) foot tapping (MTAN .005). The following variables also have an influence: hand tapping (MTAR .008), mixed pull-ups (MMZG .008) and squats (MČUČ .009), however, this significance is not at a statistically significant level of $(\mathrm{p}<0.05)$. The obtained results of partial regression (Beta) and its significance (p), indicate that the subjects will achieve better results in the $100 \mathrm{~m}$ sprints (TR 100), if they have better motor skills.

\section{Discussion}

The primary aim of the study was to determine the influence of motor skills on the $100 \mathrm{~m}$ running results. Results were obtained that show that there is a statistically significant influence of motor skills (predictor variables) on the $100 \mathrm{~m}$ sprint results (criterion variables) at the level of $(p=.000)$. Variable for estimating explosive power: standing long jump (MSDM) and segmental speed variables: foot tapping on the wall (MTAZ) and foot tapping (MTAN) have a statistically significant effect on the $100 \mathrm{~m}$ running results (TR 100). The variables also have a significant influence: hand tapping (MTAR), mixed 
Table 4. Statistical significance parameters for the assessment of 100 sprints

\begin{tabular}{lllll}
\hline Variables & $\mathbf{R}$ & Part-R & Beta & $\mathbf{p}$ \\
\hline MSDM & -0.36 & -0.12 & -4.15 & .002 \\
MTRS & -0.16 & -0.16 & -1.42 & .188 \\
MPTS & 0.16 & 0.16 & 1.50 & .210 \\
MTAN & -0.38 & -0.35 & -3.90 & .005 \\
MTAR & -0.31 & -0.24 & -3.71 & .008 \\
MTAZ & -0.28 & -0.18 & -3.63 & .003 \\
MDTK & 0.17 & 0.18 & 1.44 & .155 \\
MMZG & -0.59 & -0.50 & -3.75 & .008 \\
MČUČ & 0.51 & 0.50 & 3.80 & .009 \\
MDPK & -0.11 & -0.11 & -0.05 & .268 \\
MŠPA & -0.15 & -0.15 & -1.40 & .198 \\
MISP & -0.12 & -0.12 & -1.16 & .170 \\
\hline
\end{tabular}

Note: correlation coefficient (R), partial correlation coefficient (Part-R), standardized partial regression coefficient (Beta), level of significance (p); standing long jump (MSDM), triple jump (MTRS), five jump (MPTS), foot tapping (MTAN), hand tapping (MTAR), foot tapping on the wall (MTAZ), lifting the torso on the Swedish bench (MDTK), mixed pull-ups (MMZG), squats (MČUČ), deep bench press (MDPK), twine (MŠPA), stick twist (MISP).

pull-ups (MMZG) and squats (MČUČ), however, this significance is not at a statistically significant $(p<0.05)$. Therefore, the obtained results indicate that the success in $100 \mathrm{~m}$ short sprints mostly depends on the explosive power and segmental speed.

The results obtained in this way can be said to be expected, because the most important factors for achieving high results of short sprints are the speed of alternative movements, explosive power as well as maximum strength, acquired in squats and strength exercises, is significantly associated with the effect of sprints. The end result of running short sprints depends on the speed of reaction at the start, the ability to show speed in the shortest possible time, as well as on maintaining the maximum speed reached to the finish line [25]. The obtained results can be explained by the fact that in the stage of running at maximum speed on short sprints, the most important structural element of movement is active reflection with the reflecting leg and fast pulling upwards of the swinging leg, previously maximally bent at the knee joint in the phase of the last swing. At the end of the flight phase, the runner performs a downward action with the swinging leg, stretching the leg at the knee and touching the ground with the front part of the foot, and with the reflecting leg, which bends at the same time, it approaches the swinging leg [5]. Also, the high level of explosive power of the lower extremities is positively related to acceleration [26]. Aksović [18] showed that motor skills: speed, power, as well as maximum force of tried movements have a great influence on the results of short sprints in relation to motor abilities: precision, balance, coordination and flexibility, which have less influence in relation to the above motor skills [18]. Maćkala et al. [27] showed a strong correlation between explosive power and short sprints, indicating that step frequency is the most important factor in the development of maximum speed during the initial and secondary phases of acceleration [27]. Biomechanical factors such as: reaction time, techniques, electromyography (EMG), force production, neuronal factors and muscle structure have a significant role in the short sprint. At the beginning of a sprint run, it is important to produce a lot of force and generate a lot of speed in the acceleration phases. During the constant speed phase, activities immediately before and during the stopping phase are important to increase the explosive force/power and efficiency of movement in the propulsion phase. However, there are no studies that have examined the production of force in the phase of sprint acceleration and sprint deceleration, which is a recommendation for future researchers [28].

\section{Conclusions}

The research was conducted with the aim of determining the influence of motor skills on the $100 \mathrm{~m}$ running results. Using regression analysis, the results were obtained to confirm that there is a positive influence of motor skills on the $100 \mathrm{~m}$ sprint results at the level of significance $(p=.000)$. Variable for estimating explosive power: standing long jump and segmental speed variables: foot tapping on the wall and foot tapping have a statistically significant effect on the criterion variable of $100 \mathrm{~m}$ running results. It can be concluded that the results in the $100 \mathrm{~m}$ sprints are statistically significantly dependent on the motor skills that manifest segmental speed and explosive power. Recommendation to future researchers would be to conduct a study over a longer period of time with the aim of examining the biomechanical factors that determine the success in sprints, i.e., the production of force in the 
phase of sprint acceleration and sprint deceleration. The theoretical and practical value of this research is that high school physical education teachers will increase the level of information on the influence of motor skills on the 100 $\mathrm{m}$ running results, which will lead to better results in the realization of program tasks of developing abilities and traits and motor skills of students.

\section{Highlights}

- positive influence of motor skills on the $100 \mathrm{~m}$ sprint results at the level of significance;
- standing long jump, foot tapping on the wall and foot tapping have a statistically significant effect on the criterion variable of $100 \mathrm{~m}$ running results;

- the results in the $100 \mathrm{~m}$ sprints are statistically significantly dependent on the motor skills that manifest segmental speed and explosive power.

\section{Funding}

No funds were provided.

\section{Conflicts of interest}

All authors have no conflicts of interest.

\section{References}

1. Višnjić D. Nastava fizičkog vaspitanja od V do VIII razreda osnovne škole: priručnik za studente, nastavnike i profesore [Physical education classes: from $5^{\text {th }}$ to $8^{\text {th }}$ grade of primary school: a handbook for students, teachers and professors]. Serbian, Belgrade: Institute for Textbooks and Teaching Aids; 2006. (In Bosnian).

2. Aksović N, Bjelica B, Jovanović Lj, Zelenović M, D’Onofrio R. Methodological-organizational forms of work in physical education teaching. Italian Journal of Sports Rehabilitation and Posturology, 2021; 10(24): 2436-2451.

3. Simeonov A, Dzambazovska-Stardelova M, Pavlovikj $\mathrm{R}$. The influence and differences of anthropometric characteristics and motor skills in two generation students in the athletic discipline - high jump. European Journal of Physical Education and Sport Science, 2020;9:31-8. https://doi.org/10.46733/PESH20920031s

4. Ramabaja Q, Rashiti N, Shkodra M, Ramadani, L. The impact of some morphological and motor characteristics in short distance running. Journal of Education, Health and Sport, 2021;11(6):109-119;. https://doi.org/10.12775/ JEHS.2021.11.06.012

5. Aksović N. Uticaj motoričkih sposobnosti na rezultate $u$ kratkom sprintu [The influence of motor abilities on results in short sprint]. [Master's thesis]. Serbian, Novi Pazar: Faculty of Sport and Physical Education; 2012. (In Bosnian).

6. Arunović D, Berković L, Bokan B, Krsmanović B, Madić B, Radovanović Đ. et al. Fizičko vaspitanje, Teorijskometodičke osnove stručnog rada [Physical education, Theoretical and methodical bases of professional work]. Serbian: Niš: Sirius; 1992. (In Bosnian).

7. Babić V, Čoh M. Karakteristike razvoja brzine i sprinterskog trčanja [Characteristics of speed development and sprint running]. Proceedings of the VIII International Scientific Conference "Fitness training of athletes". Croatian, Zagreb: Faculty of Kinesiology, University of Zagreb; 2010. (In Bosnian).

8. Dahl J, Degens H, Hildebrand F, Ganse B. Age-related changes of sprint kinematics. Frontiers in Physiology, 2019; 10: 613. https://doi.org/10.3389/fphys.2019.00613

9. Lum D, Aziz AR. Relationship between isometric force-time characteristics and sprint kayaking performance. International Journal of Sports Physiology and Performance, 2020; 16(4), 474-479. https://doi.org/10.1123/ijspp.2019-0607

10.Iaia FM, Fiorenza M, Larghi L, Alberti G, Millet GP, Girard O. Short-or long-rest intervals during repeatedsprint training in soccer? PloS one, 2017; 12(2): e0171462. https://doi.org/10.1371/journal.pone.0171462

11. Aksović N, Berić D, Kocić M, Jakovljević S, and Milanović F. Plyometric training and sprint abilities of young basketball players. Facta Universitatis, Series: Physical Education and Sport, 2020; 17(2): 539-548. https://doi.org/10.22190/FUPES190315048A

12.Del Vecchio L, Stanton R, Reaburn P, Macgregor C, Meerkin J, Villegas $\mathrm{J}$ et al. Effects of combined strength and sprint training on lean mass, strength, power, and sprint performance in masters road cyclists. The Journal of Strength \& Conditioning Research, 2019; 33(1): 66-79. https://doi.org/10.1519/JSC.0000000000001960

13.Haugen TA, Breitschädel F, Seiler S. Sprint mechanical properties in handball and basketball players. International Journal of Sports Physiology and Performance, 2019; 14(10): 1388-1394. https://doi.org/10.1123/ijspp.2019-0180

14.Fiorilli G, Mariano I, Iuliano E, Giombini A, Ciccarelli A, Buonsenso A et al. Isoinertial eccentric-overload training in young soccer players: Effects on strength, sprint, change of direction, agility and soccer shooting precision. Journal of Sports Science \& Medicine, 2020; 19(1): 213.

15.Wilmore JH, Costill DL. Physiology of sport and exercise. Leisure Press, Champaign IL: Human Kinetics; 1994. https://doi.org/10.1249/00005768-199505000-00024

16.Stojiljković S. Osnove opšte antropomotorike [Fundamentals of general anthropomotorics]. Serbian, Niš: Student Cultural Center Niš; 2003. (In Bosnian).

17.Iseni A, Ameti V, Memishi S. The Effect of Motor Skills in The Success of Sprint Running. Sport And Health, 2020;7(13-14), 9-18.

18.Aksović N. Efekti pliometrijskog treninga na eksplozivnu snagu, sprint i brzinu promene pravca mladih košarkaša [The effects of plyometric training on explosive power, sprint and change of direction speed of young male basketball players]. [PhD Thesis]. Serbian, Niš: Faculty of Sport and Physical Education; 2019. (In Bosnian).

19.Shen W. The effects of stride length and frequency on the speeds of elite sprinters in 100 meter dash. Biomechanical proceedings of XVIII International Symposium of Biomechanics in Sports (ISBS). Hong Kong; 2000. P.333336.

20.Gajer B, Thepaut-Mathieu C, Lehenaff D. Evolution of stride and amplitude during course of the $100 \mathrm{~m}$ event in athletics. New Studies in Athletics, 1999; 14(1): 43-50.

21.Brüggemann GP, Koszewski D, Müller H. Biomechanical research project: Athens 1997, final report. Oxford: Meyer \& Meyer Sport, 1999; 12-41.

22.Kurelić N. Struktura i razvoj morfoloških $i$ motoričkih dimenzija omladine [Structure and development of morphological and motor dimensions of youth]. Serbian, Belgrade: Faculty of Physical Education; 1975. (In Bosnian).

23.Tončev I. Razvoj izdržljivosti kod trkača [Development of endurance in runners]. Serbian, Novi Sad: Faculty of Physical 
Education; 1983. (In Bosnian).

24.Mihajlović I, Tončev I. Predictive values of morphologoical and motor system for sprint selection purposes. Acta Kinesiologica, 2008; 2(1): 95-98.

25.Nikolić D. Kompleksni trening mladih košarkaša [Complex training of young basketball players]. [PhD Thesis]. Serbian, Niš: Faculty of Sport and Physical Education; 2016. (In Bosnian).
26.Maćkała K, Fostiak M, Kowalski K. Selected determinants of acceleration in the $100 \mathrm{~m}$ sprint. Journal of Human Kinetics, 2015; 45: 135. https://doi.org/10.1515/hukin-2015-0014

27.Mero A, Komi PV, Gregor RJ. Biomechanics of sprint running. Sports Medicine, 1992; 13(6): 376-392. https://doi.org/10.2165/00007256-199213060-00002

\section{Information about the authors:}

Nikola Aksović; https://orcid.org/0000-0002-5312-3456; kokir87np@gmail.com; Faculty of Sport and Physical Education, University of Niš; Serbia.

Iryna Skrypchenko; https://orcid.org/0000-0001-5895-3099; sit71@ukr.net; Department of Physical Education \& Tactical and Special Training, Dnipropetrovsk State University of Internal Affairs Ukraine; Ukraine.

Bojan Bjelica; https://orcid.org/0000-0001-5539-8210; vipbjelica@gmail.com; Faculty of Physical Education and Sport, University of East Sarajevo; Bosnia and Herzegovina.

R. Ram MOHAN SINGH; https://orcid.org/0000-0001-7553-8575; dr.rammohansingh@gmail.com; Department of Physical Education \& Sports, Pondicherry University; India.

Filip Milanović; https://orcid.org/0000-0002-9527-5204; filipmilanovic333@gmail.com; University Children's Hospital; Belgrade, Serbia.

Dejan Nikolić; https://orcid.org/0000-0002-0609-9916; denikol27@gmail.com; University Children's Hospital; Faculty of Medicine, University of Belgrade; Belgrade, Serbia.

Milan Zelenović; (Corresponding Author); https://orcid.org/0000-0003-0435-2399; milanzeleni13@gmail.com; Faculty of Physical Education and Sport, University of East Sarajevo; Bosnia and Herzegovina.

Cite this article as:

Aksović N, Skrypchenko I, Bjelica B, Mohan Singh RR, Milanović F, Nikolić D, Zelenović M. The influence of motor skills on the short sprint results. Pedagogy of Physical Culture and Sports, 2021;25(6):382-387. https://doi.org/10.15561/26649837.2021.0607

This is an Open Access article distributed under the terms of the Creative Commons Attribution License, which permits unrestricted use, distribution, and reproduction in any medium, provided the original work is properly cited (http://creativecommons.org/licenses/by/4.0/deed.en).

Received: 10.10 .2021

Accepted: 19.11.2021; Published: 30.12.2021 